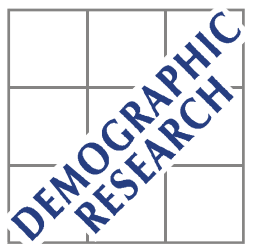

Demographic Research a free, expedited, online journal

of peer-reviewed research and commentary in the population sciences published by the Max Planck Institute for Demographic Research

Konrad-Zuse Str. 1, D-18057 Rostock · GERMANY

www.demographic-research.org

DEMOGRAPHIC RESEARCH

VOLUME 22, ARTICLE 1, PAGES 1-28

PUBLISHED 05 JANUARY 2010

http://www.demographic-research.org/Volumes/Vol22/1/

DOI: $10.4054 /$ DemRes.2010.22.1

Research Article

\title{
Extra-marital sexual partnerships and male friendships in rural Malawi
}

\section{Shelley Clark}

This publication is part of the proposed Special Collection "HIV/AIDS in subSaharan Africa", edited by Susan Watkins, Jere Behrman, Hans-Peter Kohler, and Simona Bignami-Van Assche.

(C) 2010 Shelley Clark.

This open-access work is published under the terms of the Creative Commons Attribution NonCommercial License 2.0 Germany, which permits use,

reproduction \& distribution in any medium for non-commercial purposes,

provided the original author(s) and source are given credit.

See http:// creativecommons.org/licenses/by-nc/2.0/de/ 


\section{Table of Contents}

1 Introduction 2

2 Study setting and data 5

2.1 Dependent variable 6

2.1.1 Husbands' self-reports of EMSPs 6

2.1.2 Reliability and agreement with respect to reported EMSP 7

2.2 Independent variables 8

2.2.1 Individual and marital union characteristics $\quad 8$

$\begin{array}{ll}\text { 2.2.2 Men's friendships } & 10\end{array}$

3 Methods 11

$4 \quad$ Results 13

4.1 Bivariate results 13

$\begin{array}{lll}4.4 & \text { Multivariate results } & 14\end{array}$

5 Discussion 18

$6 \quad$ Policy and programmatic implications 20

$7 \quad$ Acknowledgments $\quad 21$

$\begin{array}{ll}\text { References } & 22\end{array}$ 


\title{
Extra-marital sexual partnerships and male friendships in rural Malawi
}

\author{
Shelley Clark ${ }^{1}$
}

\begin{abstract}
Extra-marital sexual partnerships (EMSPs) are a major route of HIV/AIDS transmission in sub-Saharan Africa. In this paper, we investigate the roles of two types of male friendships - best friends and friends with whom they talk about AIDS - in determining whether men have EMSPs. Using data from men in rural Malawi, we find that men's current extra-marital sexual behavior is most closely correlated with their best friends', but that the behaviors of both types of friends are associated with men's subsequent EMSPs. These findings suggest that men's friendships could be used to help combat the AIDS epidemic.
\end{abstract}

\footnotetext{
${ }^{1}$ Associate Professor of Sociology, Canada Research Chair in Youth, Gender, and Global Health, McGill University, Stephen Leacock Building, Room 713. 855 Sherbrooke Street West, Montreal, Quebec, H3A 2T7. Phone: 514-398-8822. Fax: 514-398-3403. E-mail: shelley.clark@mcgill.ca
} 


\section{Introduction}

The spread of the AIDS crisis into the general population of married couples in much of sub-Saharan Africa has shone an increasingly intense spotlight on extra-marital sexual partnerships (EMSPs). EMSPs comprise a key group of concurrent partners, which are widely identified as one of the most important factors fuelling generalized epidemics of HIV/AIDS (Garnett and Johnson 1997; Halperin and Epstein 2004; Morris and Kretzschmar 1997, 2000; Wilson and Halperin 2008). ${ }^{2}$ Almost by definition nonmarital sexual partners of married men and women are concurrent partners, as few spouses cease having sexual relations with each other. These extra-marital partnerships can vary in length from one-night stands to decades-long relationships. Individuals who have sexual partners outside of marriage directly increase their own risk of contracting HIV and, consequently, increase the risk that they will pass the virus along to their spouse. Concurrent partnerships may further increase the risk of transmission within marriage, as individuals have higher viral loads and, thus, are more infectious shortly after contracting the virus (Quinn et al. 2000). According to a recent study in urban Zambia and Rwanda, between $55.1 \%$ and $92.7 \%$ of new heterosexually-acquired HIV infections take place within serodiscordant married or cohabiting couples (Dunkle et al. 2008).

Although both husbands and wives may have EMSPs, men are far more likely to report having sexual relationships outside of the marriage. Married men in rural Malawi, for example, are four times more likely to acknowledge having had an EMSP than married women in Malawi (Schatz 2005). Similarly large differences are reported elsewhere in Africa (Caraël et al. 1995). Part of this self-reported discrepancy may be attributable to under-reporting by women and, potentially, over-reporting by men (Nnko et al. 2004). However, prospective studies of HIV-negative couples in stable unions, which repeatedly test both members of the dyad, have found that men are twice as likely as women to first become infected with HIV and bring it into the union (Carpenter et al. 1999; Lurie et al. 2003). Presumably most of these husbands became infected from their EMSPs. Because of the potential for under-reporting of EMSPs by women, as well as their likely lower rates of having EMSPs, this paper focuses exclusively on men's EMSPs.

Among demographers and sociologists, interest in the determinants of men's extramarital relations predates the HIV/AIDS epidemic, and the topic received sporadic attention in relation to total fertility, non-marital fertility, marital dissolution, and the transmission of other STIs. Most of the literature on EMSPs has focused on the individual characteristics of men most likely to have EMSPs as well as some aspects of

\footnotetext{
${ }^{2}$ Lagarde et al. (2001) provide a dissenting view.
} 
the martial unions, particularly the practice of post-partum abstinence and polygamy. A wide spectrum of men appears to engage in extra-marital sexual relationships with few individual characteristics being consistently correlated with having EMSPs. There are a few notable exceptions. Migrant laborers report having more EMSPs due to their extended residence away from their families (Boerma et al. 2002; Chirwa 1997; Hirsch et al. 2002; Wolffers et al. 2002). Wealthier men are often suspected of having more EMSPs, partly because these men can afford payments and gifts in exchange for sexual favors. Comparing data across eight countries in sub-Saharan Africa, Mishra et al. (2007), generally find a positive association between wealth and having two or more sexual partners in the last year. In Zambia, however, no measures of wealth were found to be correlated with extra-marital sexual intercourse once control variables for region, urban residence, and age were added (Kimuna and Djamba 2005). Educational attainment's effect on extra-marital relations has been found to be positive in some studies, negative in others (Ahlburg, Jensen, and Perez 1997; Isiugo-Abanihe 1994; O'Connor 2001). Interestingly, the effect of religion on extra-marital relations appears to be context-specific, with few differences by religious affiliation within a given region. In Zambia there appears to be no effect of religious affiliation on extra-marital sexual behavior (Kimuna and Djamba 2005), although in Nigeria Muslims were found to be least likely to have EMSPs (Mitsunago et al. 2005). Arguably, an individual's degree of religiosity rather than his particular religious affiliation would have a more important effect on EMSPs. Indeed, one study among men in rural Malawi found that regular attendance at religious services is strongly negatively associated with having EMSPs (Trinitapoli and Regnerus 2006).

Aspects of the marital union may also affect the likelihood that husbands seek outside sexual partners. The practice of post-partum abstinence is widely believed to encourage the formation of EMSPs (Ali and Cleland 2001; Awusabo-Asare and Anarfi 1997; Cleland, Ali, and Capo-Chichi 1999; Glynn et al. 2001), while at least one study has also found an increased risk of male extra-marital relations during pregnancy (Onah et al. 2002). In polygamous societies, the links between EMSPs and multiple concurrent spousal partners are complex. In Nigeria, for example, Mitsunaga et al. (2005) find that men with two wives are less likely than either monogamous men or men with three or more wives to have EMSPs. Isiugo-Abanihe (1994), however, finds that Nigerian men in polygamous unions are more likely to have ever had EMSPs, but are less likely to have had EMSPs in the last week. In Malawi, Reniers and Tfaily (2008) also report a positive correlation between polygamy and having ever had EMSPs. These findings may suggest that men engage in sexual activity with prospective new brides (thus increasing their number of EMSPs); but that after marrying, polygamous men seek fewer EMSPs, e.g. during any one wife's menses, pregnancy, or the post-partum abstinence. 
One of the strongest predictors of EMSPs is region. Despite some claims that there is an African sexual system, which - partially as a consequence of polygamy - is generally accepting of married men having multiple, and often concurrent, sexual partners (Caldwell 2000), studies consistently find that there is considerable variation in the practice of having EMSPs not only across countries in sub-Saharan Africa, but also by region within countries (Caraël, Cleland, and Ingham 1994; Kimuna and Djamba 2005). At the national level, reported rates of EMSPs among married men within the last year range from as low as $4.7 \%$ in Rwanda to $28.6 \%$ in Tanzania (INSR and Marco 2006; National Bureau of Statistics and Macro 2005). Within countries, there is also marked variation. In Zambia, men living in the Southern and Western Provinces were significantly more likely to have extra-marital sex than men living elsewhere (Kimuna and Djamba 2005). In Malawi, married men are more likely to report having EMSPs in the southern region than in the northern region (National Statistical Office and Macro 2001). This strong association between the prevalence of EMSPs among men and region highlights the importance of local social norms.

Lastly, and of particular interest for this paper, men's friendships with each other may play an important role in shaping and reinforcing social norms about multiple and concurrent sexual partnerships inside and outside of marriage. In her study on young men in South Africa, Varga (1997:55) finds that "[h]aving multiple sex partners was a particular status symbol, the yardstick by which masculinity, intelligence and success were measured among one's male friends." In many parts of sub-Saharan Africa, including Malawi, definitions of masculinity are closely entwined with demonstrating sexual prowess through multiple partnerships and men are keen to discuss their "conquests" with each other (Kaler 2003). Yet the emergence and continuation of the AIDS epidemic may have led some men to challenge the ties between masculinity and multiple partnerships (Hunter 2005). The spread of evangelical religions through southern and eastern Africa has led some men to publicly admonish other men who have many sexual partners, particularly if these partners are concurrent. Detailed accounts of men's informal conversations with each other in southern Malawi show that men openly express a wide range of opinion with each other regarding EMSPs. Although strict sexual monogamy is not commonly endorsed in these conversations, other means of risk reduction including partner reduction and more careful partner selection are mentioned frequently (Kaler 2004; Watkins 2004).

These qualitative studies suggest that men's friendships and conversations with each other may have a direct effect on men's behaviors with respect to EMSPs. If these claims are true, then regardless of whether particular sets of friends encourage or discourage EMSPs, we would expect to find an empirical correlation between men's own non-marital sexual behaviors and their friends' behaviors (or at least their beliefs about their friends' behaviors). Failure to find such associations would undermine prior 
claims that these conversations among men matter at all in modifying behaviors. Interpreting any existing correlation, however, requires caution. Any correlation between men and their friends could reflect either that 1) their friends are deliberately chosen because they share similar values and behaviors, a concept in the social networks literature known as homophily (Billy and Udry 1985; McPherson, SmithLovin, and Cook 2001); or 2) their friends exert "social influence" on each other's behaviors (as is usually implied in the qualitative literature). Since both homophily and social influence are theoretically likely to be stronger with respect to best friends than more casual friends, we would expect that this correlation is likely to be stronger the closer the friendship. Furthermore, if male friends exert social influence on one another, then the non-marital sexual behaviors of friends should be associated with whether or not men will change their non-marital behaviors in the future.

\section{Study setting and data}

The small country of Malawi is one of the poorest in the world, depending mainly on subsistence farming and fishing in Lake Malawi, which flanks its eastern border. Like many of its neighbors, Malawi is experiencing an HIV/AIDS epidemic, with estimated HIV prevalence rates of $17.1 \%$ in urban centers and $10.8 \%$ in rural areas (National Statistical Office and Macro 2005). As in many other countries, sexual relationships outside of marriage are considered one of the primary behaviors fuelling the epidemic. When asked to identify their primary risk for contracting AIDS, 52\% of wives said it was their spouse and $38 \%$ of married men stated that another (non-spousal) partner was their primary source of risk (Watkins 2004). Thus both husbands and wives view men's EMSPs as an important source of risk.

To investigate the key predictors of men's EMSPs, we use a unique set of longitudinal data on matched married couples in rural Malawi. These data come from the first two waves of the Malawi Diffusion and Ideational Change (MDIC) survey conducted in 1998 and 2001. The structure of these data, their substantive focus, and data quality are described by Watkins et al. (2003). A random sample of married women and their husbands was collected in three rural sites located in a northern district (Rumphi), central district (Mchinji), and southern district (Balaka). These data capture much of the diversity in ethnicity, religion, and lineage systems in Malawi.

Our sample consists of 1,037 currently married men in 1998 and 935 currently married men in 2001. In our longitudinal analyses, we limit our sample to 722 men who were interviewed in both waves of the survey. Our own analyses revealed few differences between the sample in 1998 and the longitudinal sample. Furthermore, multivariate analyses of individuals lost to attrition in the second wave of the survey 
found no systematic attrition for men by observed characteristics (Bignami-Van Assche, Reniers, and Weinreb 2003).

\subsection{Dependent variable}

\subsubsection{Husbands' self-reports of EMSPs}

In both survey rounds, husbands were asked whether they had had sexual intercourse with anyone other than their wife (wives) in the last 12 months. Polygamous men were explicitly instructed not to include any of their wives as EMSPs. Slightly less than $10 \%$ of husbands in both 1998 and 2001 acknowledged having had EMSPs in the preceding year (Table 1). In comparison, the nationally representative Demographic Health Survey from Malawi conducted in 2000 found that a much higher percentage of men in rural Malawi (17\%) reported having had an EMSPs in the last year (National Statistical Office and Macro 2001). Such differences may reflect the design and specific location of our survey. Men who acknowledged having had an EMSP reported having had about 2.4 EMSPs in 1998 and 1.8 in 2001.

Table 1: Description of dependent variables.

\begin{tabular}{lrrr}
\hline & Yes & No & \multicolumn{1}{c}{$\boldsymbol{n}$} \\
& (\%) & (\%) & \\
\hline Husband reported EMSPs in last year (1998) & 9.0 & 91.0 & 1,037 \\
Husband reported EMSPs in last year (2001) & 8.9 & 91.1 & 935 \\
Husband changed reported EMSP behavior between surveys & 13.3 & 86.7 & 722 \\
\hline
\end{tabular}

Husbands' reports of having had an EMSP in the last year in both 1998 and 2001 serve as our main dependent variables. In addition, since we are interested in how men's behaviors may change over time, we also examine the proportion of husbands who report different behaviors with respect to their EMSPs in 1998 and 2001. In our final analyses, the dependent variable equals " 1 " if the respondent changed his behavior with respect to EMSPs between 1998 and 2001 (i.e. if the respondent had an EMSP in 1998 but not in 2001 or vice versa) and " 0 " if the respondent reported identical behavior in each survey. Not surprisingly the majority of men reported the same behavior in both waves $(86.7 \%$ ), while $13.3 \%$ report changing their behaviors between surveys. We note that about half of men who changed their EMSP status between 1998 and 2001 switched from having EMSPs to being monogamous, and the other half changed from being monogamous to having EMSPs. 


\subsubsection{Reliability and agreement with respect to reported EMSP}

Since research on extra-marital relations is notoriously fraught with respondent misreporting, Table 2 explores the reliability of these data. In the second wave conducted in 2001, husbands were also asked whether they had ever had any sexual partners besides their spouse during the course of their marriage. Table 2 compares men's self-reports of having ever had an EMSP in 2001 to men's self-reports of having had an EMSP in the last year in both 2001 and 1998. Questions about having ever had EMSPs and having had EMSPs in the last year were asked at different points in the interview process in 2001. When asked at the beginning of the survey whether they had ever had an EMSP, $81.5 \%$ of men in 2001 claimed that they never had an EMSP. Later in the survey, however, $3.2 \%$ of these men gave the inconsistent response that they had had an EMSP in the last year. In comparison, over 30\% of men who said they had had a previous EMSP also claimed to have had an EMSP in the last year. As an even stricter test of reliability, we also compare men's reports of having ever had an EMSP in 2001 with their reports of having had an EMSP in the last year in 1998. Again, we find substantial consistency between these different reports. Of those who reported never having had an EMSP in 2001, 5.6\% indicated three years earlier in 1998 that they had had an EMSP in the preceding year. Among those men who acknowledged having had an EMSP during the course of their relationship 17.5\% also said they had had an EMSP in the year preceding 1998.

As a further assessment of the reporting on EMSPs, we compare husbands' reports of having ever had EMSPs to their matched wives' suspicions about whether they have ever had EMSPs reported in 2001. Even with full disclosure by both spouses, we would not expect perfect agreement between these two measures, as some wives may simply not know whether or not their husbands have had non-marital sexual partners. Nonetheless, Table 2 shows that wives are significantly more likely to suspect husbands who report having ever had an EMSP than those who do not. Among men who report having had EMSP, almost three-quarters are suspected to some degree by their wives of having an EMSP. In contrast, among men who profess to never have had an EMSP, less than half (42.6\%) are suspected by their wives. Even after controlling for other individual, marital union, and social network characteristics, if a husband reports he has ever had an EMSP, the odds of being suspected by his wife increase threefold (results not shown). Overall, Table 2 indicates that wives exhibit some ability to identify unfaithful husbands, although their predictions are by no means perfect. Overall, wives tend to substantially over-estimate the probability that their husbands have EMSPs. 
Table 2: Comparing measures of husbands' EMSPs

\begin{tabular}{|c|c|c|c|c|}
\hline & \multicolumn{3}{|c|}{$\begin{array}{c}\text { Husbands' reports of ever having } \\
\text { EMSP (2001) }\end{array}$} & \multirow[b]{2}{*}{ Sig. } \\
\hline & Yes & No & Total & \\
\hline Husband's report of EMSP in last year (2001) & \multicolumn{2}{|c|}{$(n=935)$} & & $* * *$ \\
\hline Yes & 34.1 & 3.2 & 8.9 & \\
\hline No & 65.9 & 96.9 & 91.1 & \\
\hline Husband's report of EMSP in last year (1998) & \multicolumn{2}{|c|}{$(n=626)^{1}$} & & $* * *$ \\
\hline Yes & 17.5 & 5.6 & 8.0 & \\
\hline No & 82.5 & 94.4 & 92.0 & \\
\hline Wife's suspicion about husband's EMSP (2001) & \multicolumn{2}{|c|}{$(n=789)^{2}$} & & $* * *$ \\
\hline Yes & 38.2 & 15.5 & 51.2 & \\
\hline Suspects & 12.7 & 7.6 & 20.2 & \\
\hline Can't tell & 22.9 & 19.5 & 8.6 & \\
\hline Probably not & 26.1 & 57.4 & 20.0 & \\
\hline
\end{tabular}

1. Excludes husbands not internviewed or married less than one year in 1998

2. Excludes husbands whose wives were not interviewed in 2001

Significance: ${ }^{* \star *}=p<0.001$

\subsection{Independent variables}

\subsubsection{Individual and marital union characteristics}

Our analyses examine several individual and marital union characteristics, which the previous literature suggests may be associated with EMSPs. At the individual level, these include age, educational attainment, and religious affiliation. The majority of our sample (over 60\%) had received some primary school education (Table 3). More than half of our sample identified as being Protestant, which includes several evangelical sects. About one-quarter were Muslim and one-fifth Catholic. In addition to religious affiliation, the second wave of the survey added a question about when the respondent last attended a religious service. We use recent attendance as an indicator of greater religiosity. Economic status is measured by two variables. As one measure, we record the ownership of five common household items including a mattress, radio, bicycle, latrine, and paraffin lamp. On average, married men owned 2.7 of these items in 1998 and 3.0 in 2001. Housing conditions, which also reflect economic status, improved over time with a higher proportion of men living in brick rather than mud huts by 2001 .

In addition, we examine several key marital union characteristics, including marital duration, whether the marriage is currently polygamous, and whether the husband usually resides in the household. From the data in 2001, we also evaluate 
whether the man acquired an additional wife in the last year. Because much of the previous research on EMSPs focused on the role of pregnancy and post-partum abstinence, we include a dummy variable for whether a child was born within the last year and a continuous variable for the total number of children.

\section{Table 3: $\quad$ Characteristics of husbands, by their EMSP status}

\begin{tabular}{|c|c|c|c|c|c|c|c|c|}
\hline \multirow[b]{2}{*}{ Independent variables } & \multicolumn{3}{|c|}{1998} & \multirow[b]{2}{*}{ Sig } & \multicolumn{3}{|c|}{2001} & \multirow[b]{2}{*}{ Sig } \\
\hline & No EMSP & EMSP & Total & & No EMSP & EMSP & Total & \\
\hline $\bar{n}$ & 944 & 93 & 1037 & & 852 & 83 & 935 & \\
\hline \multicolumn{9}{|l|}{ Individual characteristics } \\
\hline Age (ave) & 37.6 & 31.8 & 37.1 & $\star \star *$ & 40.5 & 36.1 & 40.1 & $\star \star * *$ \\
\hline Education (\%) & & & & * & & & & \\
\hline None & 22.6 & 16.1 & 22.0 & & 17.2 & 14.5 & 16.9 & \\
\hline Primary & 63.6 & 60.2 & 63.3 & & 68.4 & 66.3 & 68.2 & \\
\hline Secondary & 13.9 & 23.7 & 14.8 & & 14.5 & 19.3 & 14.9 & \\
\hline Religion (\%) & & & & & & & & $* \star *$ \\
\hline Catholic & 19.0 & 9.7 & 18.1 & & 17.1 & 27.7 & 18.0 & \\
\hline Protestant & 50.9 & 59.1 & 51.6 & & 56.9 & 32.5 & 54.8 & \\
\hline Muslim & 22.1 & 23.7 & 22.3 & & 19.3 & 33.7 & 20.6 & \\
\hline Other & 8.1 & 7.5 & 8.0 & & 6.7 & 6.0 & 6.7 & \\
\hline Religiosity & & & & & & & & ** \\
\hline Attend in last week & na & na & na & & 66.8 & 55.4 & 65.8 & \\
\hline Attend in last 6 months & na & na & na & & 27.9 & 30.1 & 28.1 & \\
\hline Attend more than 6 months ago & na & na & na & & 5.3 & 14.5 & 6.1 & \\
\hline Ownership of consumer goods (ave) & 2.7 & 2.6 & 2.7 & & 3.0 & 3.0 & 3.0 & \\
\hline Household material (\%) & & & & & & & & ** \\
\hline Mud & 54.8 & 62.4 & 55.5 & & 49.8 & 32.5 & 48.2 & \\
\hline Sun or fire brick & 45.2 & 37.6 & 44.5 & & 50.2 & 67.5 & 51.8 & \\
\hline \multicolumn{9}{|l|}{ Marital union characteristics } \\
\hline Marriage duration, years (ave) & 10.8 & 7.3 & 10.5 & $\star \star \star$ & 13.2 & 10.0 & 12.9 & ** \\
\hline Polygamous union (\%) & 13.9 & 12.9 & 13.9 & & 17.7 & 18.1 & 17.7 & \\
\hline New wife in last year (\%) & na & na & na & & 2.0 & 6.2 & 2.4 & * \\
\hline Child born in last year (\%) & 36.4 & 41.9 & 36.9 & & 37.3 & 50.6 & 37.3 & * \\
\hline Number of children (ave) & 4.0 & 2.9 & 3.9 & & 4.7 & 3.8 & 4.6 & * \\
\hline Husband resides in hh (\%) & 94.2 & 90.3 & 93.8 & & 96.1 & 92.8 & 95.8 & \\
\hline \multicolumn{9}{|l|}{ Friend's characteristics } \\
\hline Best friends (\%) & & & & $\star \star \star *$ & & & & *** \\
\hline Does not have EMSP & 75.0 & 39.8 & 71.8 & & 60.9 & 29.3 & 58.1 & \\
\hline Has ESMP & 14.9 & 54.8 & 18.4 & & 29.1 & 65.9 & 32.4 & \\
\hline Don't know about EMSP & 10.2 & 5.4 & 9.8 & & 10.0 & 4.9 & 9.5 & \\
\hline Friends(\%) & & & & $\star \star \star$ & & & & \\
\hline Does not have EMSP & 70.7 & 56.9 & 69.4 & & 59.1 & 52.0 & 58.6 & \\
\hline Has ESMP & 12.9 & 30.8 & 14.6 & & 20.2 & 30.0 & 20.9 & \\
\hline Don't know about EMSP & 16.5 & 12.3 & 16.1 & & 20.7 & 18.0 & 20.5 & \\
\hline No discussion of AIDS (\%) & 35.0 & 30.1 & 34.5 & & 27.4 & 39.8 & 28.5 & * \\
\hline Region (\%) & & & & & & & & $* * \star$ \\
\hline Balaka (South) & 34.0 & 30.1 & 33.7 & & 25.5 & 51.8 & 27.8 & \\
\hline Mchinji (Central) & 35.7 & 44.1 & 36.5 & & 41.7 & 24.1 & 40.1 & \\
\hline Rumphi (North) & 30.3 & 25.8 & 29.9 & & 32.9 & 24.1 & 32.1 & \\
\hline
\end{tabular}

Significance: ${ }^{*}=p<0.05,{ }^{* *}=p<0.01,{ }^{* *}=p<0.001$ 


\subsubsection{Men's friendships}

Since we are particularly interested in exploring possible relationships between men's friendships with each other and their EMSPs, we developed measures for two distinct types of male friends who may potentially influence men's decision to have EMSPs. First, all respondents where asked whether their best friend has "slept with anyone other than his wife in the last 12 months." Responses were categorized as 1= "no", 2 = "yes", and 3 = "don't know." Overall, 18.4\% of men in 1998 and $32.4 \%$ of men in 2001 believed that their best friend had had EMSPs. Less than $10 \%$ of men indicated that they didn't know whether or not their best friend had done so.

The second measure captures men's beliefs about the EMSPs of friends with whom they chatted about AIDS. All respondents were asked to provide extensive information on up to four individuals, other than their spouse, with whom they "chatted" about AIDS. Respondents were then asked how close there were to each person, defining them as an acquaintance (ongodzuwananaye), just a friend (mzanga), or a confidant (mzanga weniweni). ${ }^{3}$ For our measure, we identified the first male acquaintance or just friend mentioned by the respondent. We excluded all best friends and confidants to distinguish this type of friend from best friends. ${ }^{4}$ A small proportion of men only spoke with confidants or best friends about AIDS, while about $30 \%$ of men did not chat with anyone about AIDS. We include a dummy variable for men who did not have a friend or acquaintance in their AIDS networks. For the sake of brevity, we henceforth refer to "friends with whom they chatted about AIDS" as simply "friends." It is important to bear in mind, however, that these friends are not representative of men's broader circle of friendships, but rather of a specific type of friendship through which men are most likely to receive information about AIDS.

As with men's best friends, respondents were asked whether they believed that their friends had EMSPs. Overall, we find that men are more likely to say that they don't know whether their friends had EMSPs $(16.1 \%$ in 1998 and $20.5 \%$ in 2001) compared to their best friends $(<10 \%)$. However, they were somewhat less likely to think that they had had EMSPs (14.6\% in 1998 and 20.9\% in 2001). As a result, the proportion of best friends and friends who were believed to be sexually monogamous was approximately the same, although there was a noticeable decline in perceived sexual fidelity of both types of friends from 1998 and 2001.

\footnotetext{
${ }^{3}$ The terms indicated in the parentheses are in ChiChewa. Similar terms in Yao and Tumbuka were used depending on the region and native language of the respondent.

${ }^{4}$ About $40 \%$ of men mentioned their best friends as someone with whom they chatted about AIDS and about $90 \%$ of these best friends were identified as being confidants. The small proportion of best friends identified as just friends were also removed from this measure.
} 
For our last analyses, we also created a dummy variable to indicate whether the respondent's best friend is perceived to behave differently from himself in 1998. This variable equals " 1 " if the respondent reported that he did not have an EMSP in the last year, but he believed his best friend did. It also equals " 1 " if the respondent acknowledged having an EMSP, but thinks his friend was sexually monogamous. If the respondent perceived that he and his best friend behaved similarly in 1998, this variable was coded as " 0 ". 5 An analogous indicator variable was also created with respect to respondents' friends and acquaintances. Approximately $20 \%$ of respondents' best friends and friends were believed to have different non-martial sexual behaviors than the respondent.

\section{Methods}

Our models use logistic regressions to explore which characteristics of men, including their marital union and friendship characteristics, are associated with having EMSPs in the last year. In these models, $\pi_{i}$ is the probability that husband $i$ had an EMSP in the last year. Logistic models are run separately for each wave of the survey in 1998 and 2001.

Our basic multivariate logistic model is:

$$
\ln \left(\frac{\pi_{i}}{1-\pi_{i}}\right)=\mathbf{X}_{\mathbf{i}} \boldsymbol{\beta}_{\mathbf{1}}+\mathbf{M} \mathbf{U}_{i} \boldsymbol{\beta}_{\mathbf{2}}+\mathbf{B} \mathbf{F}_{\mathbf{i}} \boldsymbol{\beta}_{\mathbf{3}}+\mathbf{F}_{\mathbf{i}} \boldsymbol{\beta}_{\mathbf{4}}+\beta_{5} D_{i}+u_{i}
$$

where:

$$
\begin{array}{ll}
\mathrm{X} & =\text { Observed individual characteristics, } \\
\mathrm{MU} & =\text { Observed marital union characteristics, } \\
\mathrm{BF} & =\text { Perceptions about best friends' EMSPs, } \\
\mathrm{F} & =\text { Perceptions about friends' EMSPs, } \\
\mathrm{D} & =\text { Dummy for not chatting with any friends about AIDS, and } \\
\mathrm{u}_{\mathrm{i}} & =\text { Error. }
\end{array}
$$

Of primary interest is whether the perceived non-marital sexual behaviors of men's best friends and their other friends are correlated with having EMSPs, and whether this correlation is stronger with best friends than "just friends." As mentioned above,

\footnotetext{
${ }^{5}$ For these analyses, we restricted our sample to 722 men interviewed in both waves. We also removed 136 respondents who did not know whether their best friend or friend had an EMSP.
} 
finding such a correlation could reflect either that male friends influence one another's behaviors (social influence) or that men seek out the company of men with similar behaviors (homophily). A third option, however, is that this correlation is spurious. Specifically, unobserved factor(s) may be driving both men's and their friends' behaviors. For example, men who live within close geographic proximity to local services such as bars, restaurants, and trading centers may be more likely to engage in extra-marital sex. If geographic proximity also influences the selection of men's friends, then our cross-sectional estimates of the relationship between men's EMSPs and those of their friends will be biased.

To minimize the potential confounding effects of time-constant unobserved variables, we employ a fixed-effects model estimated using the xtlogit command in Stata Version 10.0. ${ }^{6}$ In the fixed-effects model below, $\alpha_{i}$ refers to the unobserved individual effects, which are removed from the error term. As a result, we can interpret the coefficients on BF and F as measuring the relationship between men's EMSPs and their friends' EMSPs controlling for all time-constant variables, such as geographic location.

$$
\ln \left(\frac{\pi_{i t}}{1-\pi_{i t}}\right)=\mathrm{X}_{\mathrm{it}} \beta_{1}+\mathrm{MU}_{i t} \beta_{2}+\mathrm{BF}_{\mathrm{it}} \beta_{3}+\mathrm{F}_{\mathrm{it}} \beta_{4}+\beta_{5} D_{i}+\beta_{6} \text { Year }_{i t}+\alpha_{i}+u_{i t}
$$

Unfortunately, fixed-effects models also present some limitations. The main drawback of all fixed effects models is that we can no longer estimate the effects of observed time-invariant predictors such as age, marital duration, educational attainment, religion, and region of residence. (These variables are no longer included in X or MU.) Moreover, in logistic fixed effects models only individuals who experience a change over time contribute to the analyses. Dropping observations that remain static severely reduces our sample size. Because there are both advantages and disadvantages to the fixed-effects method, we report both cross-sectional and fixed-effects results.

In our final model, we further explore the possibility that men exert social influence on each other's non-marital behaviors by testing whether having a best friend or friend whose behavior with respect to EMSPs differs from that of the respondent is related to the likelihood that the respondent will change his behavior in the future. In other words, if a monogamous man has a friend who has EMSPs in 1998, is he more likely to acquire an EMSP in 2001 than a monogamous man whose friends is also monogamous? Conversely, if a man with EMSPs has friends who are monogamous in 1998, is he more likely to stop having EMSPs in 2001 than a man whose friends in 1998 also have EMSPs? Unfortunately, sample size limitations prevent us from

\footnotetext{
${ }^{6}$ Fixed effects models are presented in preference to random effects models because linear probability models with random effects do not pass the Hausman test of unobserved individual-specific effects.
} 
analyzing each of these possibilities separately; thus, the relative importance of each of these possible mechanisms cannot be assessed. All other independent variables in these models use data from 1998.

We estimate the following model, where difBF and diff indicate that respondents behave differently than their friends in 1998.

$$
\log \text { odds }\left|\Delta y_{i}\right|=\mathbf{X}_{\mathbf{i}} \boldsymbol{\beta}_{\mathbf{1}}+\mathbf{M U}_{\mathbf{i}} \boldsymbol{\beta}_{\mathbf{2}}+\beta_{3} d i f B F_{i}+\beta_{4} d i f F_{i}+\beta_{5} D_{i}+u_{i}
$$

\section{Results}

\subsection{Bivariate results}

Before turning to our multivariate regression results, we briefly discuss some of the significant bivariate associations found in Table 3. In both 1998 and 2001, having EMSPs is more common among younger men and among men with some secondary schooling (this association, however, is not significant in 2001). There also appears to be a shift in EMSPs by religious groups between 1998 and 2001. Catholics are proportionately less likely to have EMSPs in 1998 but more likely in 2001 compared to either Protestants or Muslims. Attendance at religious services is significantly negatively correlated with having EMSPs in 2001. In addition, not only are men more likely to live in brick huts in 2001, but men who live in these types of houses are significantly more likely than men living in mud houses to have EMSPs.

With respect to marital union characteristics, men who have EMSPs are in marriages of shorter duration and have fewer children. We also find that men who had an EMSP last year were more likely to have had a child in the last year than men who did not have an EMSP; however, this association is only statistically significant in 2001 $(50.6 \%$ vs. $37.3 \%)$. There is no significant association between men who are currently in polygamous unions and having EMSPs. In 2001, however, we find that husbands who took a new wife in the previous year were significantly more likely to report having had EMSPs in the previous year. Although the number of men who married a new wife in the last year is rather small, this finding sheds some light on a possible link between acquiring additional wives and having EMSPs. Unfortunately, similar data on the timing of subsequent marriages is not available in the 1998 data. However, we can compare men's reports about EMSPs in 1998 to their number of wives in 2001. Among men who had at least one EMSP in 1998, 18.5\% married an additional wife between 1998 and 2001. In contrast, only 8.9\% of men who did not have an EMSP in 1998 married again by $2001(\mathrm{p}=0.016)$. These findings suggest that, like first marriages, 
second and higher order marriages for men often follow a period of sexual relations with the prospective future bride and possibly other women.

The bivariate association between men's reports of their own EMSP and that of their best friends is quite strong in both 1998 and 2001. In 1998, more than half (54.8\%) of men who had EMSPs in the last year believe that their best friend also had EMSPs, compared to only $14.9 \%$ of men who did not have an EMSP in the last year. In 2001, men who had EMSPs were more than twice as likely to believe that their best friends had EMSPs than were men with no non-marital partnerships (65.9\% vs. $29.1 \%)$. Interestingly, in both years, men who did not have EMSPs were less likely than men who did to know whether their best friends had EMSPs. The association between men's behaviors and those of their friends with whom they chatted about AIDS is less pronounced or consistent across both years. In 1998, there is a significant positive association, with $30.8 \%$ of men who had EMSPs believing that their friend also had an EMSP, compared to only $12.9 \%$ of men without EMSPs. In 2001, this positive association remains ( $30.0 \%$ vs. $20.2 \%$ ), but is not significant at the $5 \%$ level. Instead, in 2001, we find a significant positive association between having EMSPs and not having chatted with anyone about AIDS. Finally, the expected high rate of reported EMSPs in southern Malawi is clearly evident in 2001, although not in 1998.

\subsection{Multivariate results}

Table 4 shows the logistic coefficients for whether husbands reported having had any EMSPs in the last year. Models 1 and 2 examine covariates for data from 1998 and 2001 separately, while Model 3 pools these two waves of data to explore fixed effects. The results from our multivariate models are broadly consistent with those revealed in the bivariate analyses, shown in Table 3, with the exception that marital duration, number of children, and having had a child in the last year are no longer associated with EMSPs in either wave of the survey. In addition, the positive bivariate association between residence in a brick house and EMSPs weakens and becomes insignificant in the regression model for 2001. Similar to our previous findings, however, the effect of religious affiliation, particularly the relative effect of being Catholic compared to Protestant or Muslim, switches between survey waves even after controlling for other characteristics of husbands. Consistent with previous findings (Trinitapoli and Regnerus 2006), we find that in 2001, the odds of having an EMSP for men who attended church in the last week were 15 times lower than for men who last attended church more than six months ago. In 2001, we also find that having acquired a new wife in the previous year increases the odds of having had an EMSP 4.4 times. 
Table 4: Characteristics of husbands who had EMSPs within last year (logistic regression)

\begin{tabular}{|c|c|c|c|c|c|c|c|c|c|}
\hline \multirow[t]{3}{*}{ Variables } & \multicolumn{3}{|c|}{$\begin{array}{c}1998 \\
n=1025\end{array}$} & \multicolumn{3}{|c|}{$\begin{array}{c}2001 \\
n=903\end{array}$} & \multicolumn{3}{|c|}{$\begin{array}{c}\text { Fixed-Effects } \\
n=190\end{array}$} \\
\hline & \multicolumn{3}{|c|}{ Robust } & \multicolumn{3}{|c|}{ Robust } & \multicolumn{3}{|c|}{ Robust } \\
\hline & Coef. & std. err. & Sig. & Coef. & std. err. & Sig. & Coef. & std. err. & Sig. \\
\hline \multicolumn{10}{|l|}{ Individual characteristics } \\
\hline Age & -0.06 & 0.02 & ** & -0.02 & 0.02 & & & & \\
\hline \multicolumn{10}{|l|}{ Education } \\
\hline No schooling (ref) & 0.00 & --- & & 0.00 & --- & & & & \\
\hline Primary schooling & 0.26 & 0.34 & & 0.60 & 0.41 & & & & \\
\hline Secondary schooling & 1.03 & 0.44 & * & 0.95 & 0.52 & & & & \\
\hline \multicolumn{10}{|l|}{ Religion } \\
\hline Catholic (ref) & 0.00 & --- & & 0.00 & --- & & & & \\
\hline Protestant & 1.01 & 0.45 & * & -1.51 & 0.40 & $* * *$ & & & \\
\hline Muslim & 1.51 & 0.58 & * & -1.27 & 0.51 & * & & & \\
\hline Other & 0.92 & 0.61 & & -1.98 & 0.66 & ** & & & \\
\hline \multicolumn{10}{|l|}{ Religiosity } \\
\hline Attend in last week (ref) & & & & 0.00 & --- & & & & \\
\hline Attend in last 6 months & & & & 0.42 & 0.32 & & & & \\
\hline Attend more than 6 months ago & & & & 2.70 & 0.52 & $* \star *$ & & & \\
\hline Ownership of consumer goods & 0.05 & 0.09 & & 0.14 & 0.09 & & 0.22 & 0.24 & \\
\hline \multicolumn{10}{|l|}{ Housing material } \\
\hline Mud (ref) & 0.00 & --- & & 0.00 & --- & & 0.00 & --- & \\
\hline Brick & -0.58 & 0.38 & & 0.15 & 0.40 & & -1.66 & 0.65 & * \\
\hline \multicolumn{10}{|l|}{ Marital union characteristics } \\
\hline Marriage duration (yr) & -0.01 & 0.02 & & -0.03 & 0.03 & & & & \\
\hline Polygamous union & -0.02 & 0.37 & & 0.00 & 0.44 & & 0.75 & 0.74 & \\
\hline New wife in last year & & & & 1.49 & 0.71 & * & & & \\
\hline Child born in last year & 0.29 & 0.25 & & 0.47 & 0.30 & & 0.00 & 0.45 & \\
\hline Number of children & 0.04 & 0.06 & & -0.07 & 0.07 & & -0.16 & 0.21 & \\
\hline Husband resides at home & -0.51 & 0.43 & & -0.42 & 0.56 & & -1.07 & 0.85 & \\
\hline \multicolumn{10}{|l|}{ Friend's characteristics } \\
\hline \multicolumn{10}{|l|}{ Best friends } \\
\hline Does not have EMSP (ref) & 0.00 & --- & & 0.00 & --- & & 0.00 & -- & \\
\hline Has ESMP & 1.89 & 0.26 & $\star \star \star *$ & 1.54 & 0.30 & 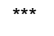 & 1.09 & 0.47 & * \\
\hline Don't know about EMSP & -0.15 & 0.54 & & -0.25 & 0.55 & & -1.05 & 0.80 & \\
\hline \multicolumn{10}{|l|}{ Friends } \\
\hline Does not have EMSP (ref) & 0.00 & --- & & 0.00 & --- & & 0.00 & --- & \\
\hline Has ESMP & 0.33 & 0.36 & & 0.19 & 0.41 & & 0.76 & 0.55 & \\
\hline Don't know about EMSP & -0.08 & 0.46 & & 0.26 & 0.45 & & 1.12 & 0.64 & \\
\hline No discussion of AIDS & 0.06 & 0.28 & & 0.63 & 0.33 & & 1.35 & 0.53 & * \\
\hline \multicolumn{10}{|l|}{ Region } \\
\hline Balaka-south (ref) & 0.00 & --- & & 0.00 & --- & & & & \\
\hline Mchinji-central & -0.32 & 0.54 & & -2.06 & 0.53 & $* * *$ & & & \\
\hline Rumphi-north & -1.05 & 0.57 & & -1.48 & 0.50 & ** & & & \\
\hline Year & & & & & & & -0.22 & 0.32 & \\
\hline Constant & -1.54 & 0.93 & & -0.95 & 1.17 & & & & \\
\hline
\end{tabular}

Significance: ${ }^{*}=p<0.05,{ }^{* *}=p<0.01,{ }^{* * *}=p<0.001$ 
Of particular interest, we find that after controlling for husbands' individual and marital union characteristics, the relationship between men's EMSPs and their beliefs about their best friends' EMSPs remains strong, while the association with their friends' behaviors diminishes and becomes insignificant. The odds that a husband reports having an EMSP are 6.6 times higher in 1998 and 4.6 times higher in 2001 if he believes that his best friend had an EMSP. In contrast, we find no significant relationship between believing that a (non-best) friend has an EMSP and the respondent's own reported behaviors, although the coefficients are positive. Interestingly, respondents who have not chatted with any friends about AIDS are marginally more likely to have EMSPs in $2001(\mathrm{p}=0.052)$.

Turning to our fixed-effects regression, we find that, among the individual characteristics, only moving from a mud to a brick house is significantly negatively associated with EMSPs. The perceived extra-marital sexual behaviors of best friends, however, continue to matter. Even after controlling for all time-constant individual characteristics, having a best friend who has an EMSP is associated with threefold higher odds of the respondent doing so, while there is no effect of having friends who have EMSPs. In addition, respondents who did not chat with at least one friend about AIDS experience a 3.9-fold increase in their odds of reporting an EMSP in the last year.

Lastly, in Table 5 we examine whether having a best friend or friend with different non-marital sexual behaviors than the respondent results in a higher probability that the respondent will change his behaviors to match those of his friends. We find evidence that the perceived behaviors of both best friends and friends affects whether or not the respondent changes his behaviors. Respondents who believe that their best friends' behaviors with respect to EMSPs differ from their own in 1998 have a 2.2 times higher odds of changing their behaviors by 2001, compared to respondents who think they and their best friends behave similarly. A slightly lower, but still significant, effect is found with respect to "just friends." 
Table 5: Characteristics of husbands who changed their non-marital sexual behaviors between 1998 and 2001 (logistic regression)

\begin{tabular}{|c|c|c|c|}
\hline \multirow[t]{2}{*}{ Variables } & \multicolumn{3}{|c|}{$n=586$} \\
\hline & Coef. & Robust std. err. & Sig. \\
\hline \multicolumn{4}{|l|}{ Individual characteristics } \\
\hline Age & -0.03 & 0.02 & \\
\hline \multicolumn{4}{|l|}{ Education } \\
\hline No schooling (ref) & 0.00 & --- & \\
\hline Primary schooling & 0.55 & 0.41 & \\
\hline Secondary schooling & 1.25 & 0.49 & * \\
\hline \multicolumn{4}{|l|}{ Religion } \\
\hline Catholic (ref) & 0.00 & --- & \\
\hline Protestant & 0.37 & 0.38 & \\
\hline Muslim & -0.18 & 0.53 & \\
\hline Other & 0.01 & 0.63 & \\
\hline Ownership of economic goods & -0.05 & 0.10 & \\
\hline \multicolumn{4}{|l|}{ Housing material } \\
\hline Mud (ref) & 0.00 & --- & \\
\hline Brick & -0.41 & 0.40 & \\
\hline \multicolumn{4}{|l|}{ Marital union characteristics } \\
\hline Marital duration (yr) & -0.03 & 0.02 & \\
\hline Polygamous union & 0.04 & 0.39 & \\
\hline Child born in last year & 0.04 & 0.28 & \\
\hline Number of children & -0.01 & 0.06 & \\
\hline Husband resides at home & -0.63 & 0.45 & \\
\hline \multicolumn{4}{|l|}{ Friendships } \\
\hline Best friend different EMSP behavior & 0.80 & 0.30 & $* *$ \\
\hline Friend different EMSP behavior & 0.71 & 0.36 & * \\
\hline No discussion of AIDS & 0.28 & 0.29 & \\
\hline \multicolumn{4}{|l|}{ Region } \\
\hline Balaka-south (ref) & 0.00 & --- & \\
\hline Mchinji-central & -1.70 & 0.56 & $* *$ \\
\hline Rumphi-north & -2.20 & 0.55 & $* * *$ \\
\hline Constant & 0.42 & 0.97 & \\
\hline
\end{tabular}

Significance: ${ }^{*}=p<0.05 .{ }^{* *}=p<0.01 .{ }^{* *}=p<0.001$ 


\section{Discussion}

As concern about the risks associated with EMSPs grows, finding factors associated with having EMSPs becomes an important policy objective. Like other investigators, we find that identifying "types" of men who have EMSPs based on easily observable characteristics is challenging. We find some weak evidence in our bivariate associations that more-educated and wealthier men are more likely to have EMSPs, and there is consistent evidence that men under the age of 35 are more likely to have EMSPs. In addition, although the effects of religious affiliation are volatile, the effects of religiosity on extra-marital partnerships are rather strong, and suggest a need for additional studies in other parts of sub-Saharan Africa.

With respect to martial union characteristics, we do not find that either being in a polygamous union or having had a child in the last year is associated with having EMSPs. In contrast, the process of acquiring a subsequent wife tends to increase husbands' reports of having EMSPs around the time of a subsequent marriage. These associations do not tell us whether men deliberately seek EMSPs with the intent of acquiring an additional wife or whether having EMSPs leads (perhaps unintentionally) to the acquisition of a new wife. However, it is clear that, as with first marriages, second and higher order marriages are often preceded by non-marital sexual intercourse. These results, while based on relatively small numbers, suggest that greater attention to the formation of polygamous unions could help minimize risks of HIV transmission via concurrent partnerships both inside and outside of marriage.

Our strongest, and arguably most important, finding is that men who believe that their best friends had EMSPs are significantly more likely to report having had EMSPs in the last year. This finding stands in contrast to the much weaker association between men and their friends with whom they chatted about AIDS. Finding that this correlation holds across both waves of our multivariate analyses and in our fixed effects model provides reassurance that this association is not spuriously driven by some other omitted factor. However, there are at least three interpretations of this relationship which warrant consideration.

First, this correlation may simply reflect projection on the part of men with respect to their friends' behaviors. In our analysis, we necessarily rely on men's perceptions about their best friends' and friends' non-marital sexual behaviors rather than their actual behaviors. These perceptions may arguably be more important to the individual's own behaviors than their friends' actual behaviors, so long as these perceptions are not merely projections of the respondent's behaviors onto others (Billy and Udry 1985). If projection is most likely to occur when individuals do not know whether a behavior occurred, then presumably men would be more aware of the actual behaviors of their best friends than that of their friends. Indeed, we find that more men say they "don't 
know" their friends' than their best friends' EMSP status. To more directly investigate the extent to which respondents' reports about their friends' EMSP behaviors agreed with their friends' self-reports, we identified 180 male respondents in the 1998 sample who were also members of other respondents' social networks. ${ }^{7}$ Among these respondents, $45 \%$ of those who reported having had an EMSP in the last year were suspected of infidelity by a social network member. In comparison, among men who reported that they had not had an EMSP in the last year, just $15.4 \%$ were suspected by their social network members (differences significant at $\mathrm{p}=0.01$ ). These analyses indicate a significant positive association between respondents' perceptions about their social network members' behaviors and the latter's actual behaviors, although men's perceptions are by no means completely accurate.

Second, if this correlation is not driven by simple projection, then another plausible explanation is that it reflects homophily. Homophily is likely to be stronger with respect to best friends than with friends with whom they talked about AIDS, as men may choose their best friends deliberately and carefully while they exhibit little discretion in selecting their conversational partners when discussing AIDS (Watkins 2004). It might not only be the case that men who have EMSPs choose a best friend because they have EMSPs; it might also be that seeking EMSPs aids in the formation of close male friendships, as it has been suggested that drinking together and then subsequently visiting sex workers may serve as a bonding experience among males (Vanlandingham et al. 1998). Conversely, men who disapprove of non-marital relationships and discover that their best friend is engaging in them may choose to "deselect" him as a close friend. Finding that about $80 \%$ of respondents report that their best friends' behavior is the same as their own suggests that there is considerable homogeneity in male friendships in terms of their extra-marital sexual behaviors.

A third possibility, however, is that male best friends may influence each other's behaviors with respect to whether or not they have EMSPs. Empirically proving social influence is notoriously difficult, but two of our findings lend credence to this interpretation. First, social influence theory predicts that behaviors of close friends should exert more influence than more distant friends. In both our multivariate crosssectional and our fixed-effects model we find a larger and stronger correlation with the perceived behaviors of best friends compared to friends. Second, we look for direct evidence of social influence by examining men's proclivity to change their behaviors over time. We find that men who have friends who behave differently from themselves are more likely to change their behaviors with respect to EMSPs than are men who report the same behavior as their friends. Specifically, one and/or both of the following changes appears to occur: 1) men who did not have EMSPs in 1998 but who believe

7 Given the widespread use of nicknames and variant name spellings, this was necessarily an imprecise exercise. Respondents with inconclusive name matches were also identified by village location. 
that their friends did are more likely to acquire EMSPs in 2001, and/or 2) men who had EMSPs in 1998, but whose friends did not, are more likely to have ceased having EMSPs in 2001, compared to men whose friends also had EMSPs in 1998.

Finding that friends with whom men chat about AIDS also appear to be influential in changing men's behaviors, raises the interesting possibility that this group of men could have social influence even though they do not exhibit much homophily. The manner in which these men may exert their influence is likely to be different from that of close friends. While best friends may be the most influential because they may mimic each other's behaviors, discussions with casual friends may lead to receiving direct (and sometimes unsolicited) advice about not only AIDS but also EMSPs.

\section{Policy and programmatic implications}

Despite the growing consensus that EMSPs are fueling the AIDS epidemic in much of sub-Saharan Africa, change in men's behaviors, specifically a reduction in their number of concurrent sexual partners, has been slow (Bertrand 2004). Uganda is often given as an example of where large declines in reported multiple partnerships coincided with a well-known "love faithfully" and "zero-grazing" campaign (Shelton et al. 2004; USAID 2002). However, while this was a public campaign that did not target particular groups of men, some researchers attribute its success to communication and mobilization through social networks (Stoneburner and Low-Beer 2004). In addition, much of the successful campaign in Thailand to reduce visits to sex workers and increase condom use with them is attributed to the positive influence of male peer groups (UNAIDS 2001; Vanlandingham et al. 1998). Peers were also found to have a similarly positive effect on the use of condoms with sex workers in Bali as well (Ford, Wirawan, and Muliawan 2002).

Our study, along with these previous findings, raises the possibility of developing effective interventions designed to change men's non-marital sexual behaviors by harnessing men's social networks, particularly their male friendships. Specifically, individuals within the social network could be targeted, a process that Valente and Fosados (2006) call sociometric segmentation, to better utilize men's social networks to promulgate messages about the risks of concurrent sexual partnerships. Several studies in the U.S. have demonstrated the effectiveness of using peer networks to reduce HIV risks associated with injecting drug use (Broadhead et al. 1998; Heckathorn et al. 1999; Zapka, Stoddard, and McCusker 1993). A recent study in Bulgaria, moreover, showed that identifying men's social network leaders and having them counsel members of their social network about safer sex was effective in reducing the rate of unprotected sex. An innovative randomized control trial of a social network-based intervention among this 
same population produced sustained lower levels of unprotected intercourse for up to one year after the intervention (Kelly et al. 2006).

Although recommending a specific type of social network-based intervention is beyond the scope of this paper, our findings suggest utilizing men's friendships with other men could prove to be an effective way of reducing risks associated with men's EMSPs. First, because men who have EMSPs tend to associate with each other, using men's ties with each other could help identify and reach men at relatively high risk of having EMSPs. Second, while we find a stronger correlation between men and their best friends, we also find that even more distant friends with whom the respondent talked about AIDS may have some effect on men's subsequent behaviors. Both of these distinct types of male friendships then may offer important venues for delivering safer sex messages, although each may also have its drawbacks. On the one hand, because of strong effects of both homophily and social influence found between best friends, recruiting best friends might be most effective. On the other hand, introducing safer sex messages may be harder in closer and more intimate social networks, and best friends may ultimately reach fewer individuals. Thus, adopting a strategy which uses men's more distant friends and acquaintances with whom they are willing to discuss issues like AIDS may be more efficient, cost-effective, and feasible from a programmatic perspective. Lastly, given the strong ties between definitions of masculinity and multiple partnerships, opinion leaders either inside or outside men's existing social networks are likely to be important to target initially. Only through the development and testing of various types of network-based interventions among men will the most effective method be identified, but our results indicate that conducting such studies should be made a funding and research priority in areas of sub-Saharan Africa afflicted by AIDS.

\section{Acknowledgments}

I would like to give particular thanks to Susan Watkins for her valuable feedback early in this project as well as to Hans-Peter Kohler for generously sharing his expertise with these data. Particularly useful comments on earlier versions of this paper were also provided by Patrick Heuveline, Jacob Levy, Alisa Lewin, Nancy Luke, Robert Michael, Marcos Rangel, and Christine Varga. Funding for the data collection was provided through the National Institute of Child Health and Human Development (NICHD) grants R01-HD37276 and R01-HD044228-01. 


\section{References}

Ahlburg, D.A., Jensen, E.R., and Perez, A.E. (1997). Determinants of extramarital sex in the Philippines. Health Transition Review 7(Supplement): 467-479. http://htc.anu.edu.au/pdfs/Ahlberg1.pdf.

Ali, M.M. and Cleland, J.G. (2001). The link between postnatal abstinence and extramarital sex in Côte d'Ivoire. Studies in Family Planning 32(3): 214-219. doi:10.1111/j.1728-4465.2001.00214.x.

Awusabo-Asare, K. and Anarfi, J.K. (1997). Postpartum sexual abstinence in the era of AIDS in Ghana: Prospects for change. Health Transition Review 7(Supplement): 257-270. http://htc.anu.edu.au/pdfs/Awusabo5.pdf.

Bertrand, J.T. (2004). Diffusion of innovations and HIV/AIDS. Journal of Health Communication 9(Suppl 1): 113-121. doi:10.1080/10810730490271575.

Bignami-Van Assche, S., Reniers, G., and Weinreb, A.A. (2003). An assessment of the KDICP and MDICP data quality: Interviewer effects, question reliability and sample attrition. Demographic Research SC1(2): 31-76. doi:10.4054/DemRes.2003.S1.2.

Billy, J.O.G. and Udry, J.R. (1985). Patterns of adolescent friendship and effects on sexual behavior. Social Psychology Quarterly 48(1): 27-41. doi: $10.2307 / 3033779$.

Boerma, J.T., Urassa, M., Nnko, S., Ng'weshemi, J., Isingo, R., Zaba, B., and Mwaluko, G. (2002). Sociodemographic context of the AIDS epidemic in a rural area in Tanzania with a focus on people's mobility and marriage. Sexually Transmitted Infections 78(Suppl 1): i97-i105. http://sti.bmj.com/cgi/reprint/78/suppl_1/i97.

Broadhead, R.S., Heckathorn, D.D, Weakliem, D.L., Anthony, D.L., Madray, H., Mills, R.J., and Hughes, J. (1998). Harnessing peer networks as an instrument for AIDS prevention: Results from peer-driven intervention. Public Health Reports 113(Suppl 1): 42-57. http://www.pubmedcentral.nih.gov/picrender.fcgi?artid $=1307726 \&$ blobtype $=$ pdf.

Caldwell, J.C. (2000). Rethinking the African AIDS epidemic. Population and Development Review 26(1): 117-135. doi:10.1111/j.1728-4457.2000.00117.x.

Caraël, M., Cleland, J., and Ingham, R. (1994). Extramarital sex: Implications of survey results for STD/HIV transmission. Health Transition Review 4 (Supplement): 153-172. 
Caraël, M., Cleland, J., Deheneffe, J.-C., Ferry, B., and Ingham, R. (1995). Sexual behaviour in developing countries: Implications for HIV control. AIDS 9(10): 1171-1175. http://journals.lww.com/aidsonline/Abstract/1995/10000/Sexual_ behaviour_in_developing_countries_.9.aspx.

Carpenter, L.M., Kamali, A., Ruberantwari, A., Malamba, S.S., and Whitworth, J.A.G. (1999). Rates of HIV-1 transmission within marriage in rural Uganda in relation to the HIV sero-status of the partners. AIDS 13(9): 1083-1089. doi:10.1097/00002030-199906180-00012.

Chirwa, W.C. (1997). Migrant labour, sexual networking, and multi-partnered sex in Malawi. Health Transition Review 7(Supplement 3): 5-15. http://htc.anu.edu.au/pdfs/Chirwa1.pdf.

Cleland, J.G., Ali, M.M., and Capo-Chichi, V. (1999). Post-partum sexual abstinence in West Africa: Implications for AIDS-control and family planning programmes. AIDS 13(1): 125-131. doi:10.1097/00002030-199901140-00017.

Dunkle, K., Stephenson, R., Karita, E., Chomba, E., Kayitenkore, K., Vwalika, C., Greenberg, L., and Allen, S. (2008). New heterosexually transmitted HIV infections in married or cohabiting couples in urban Zambia and Rwanda: An analysis of survey and clinical data. The Lancet 371(9631): 2183-2191. doi:10.1016/S0140-6736(08)60953-8.

Ford, K., Wirawan, D.N., and Muliawan, P. (2002). Social influence, AIDS/STD knowledge, and condom use among male clients of female sex workers in Bali. AIDS Education and Prevention 14(6): 496-504. doi:10.1521/aeap.14.8.496.24113.

Garnett, G.P. and Johnson, A.M. (1997). Coining a new term in epidemiology: Concurrency and HIV. AIDS 11(5): 681-683. doi:10.1097/00002030199705000-00017.

Glynn, J.R., Buvé, A., Caraël, M., Macauley, I.B., Kahindo, M., Musonda, R.M., and Zekeng, L. (2001). Is long postpartum sexual abstinence a risk factor for HIV? AIDS 15(8): 1059-1061. doi:10.1097/00002030-200105250-00016.

Halperin, D.T. and Epstein, H. (2004). Concurrent sexual partnerships help to explain Africa's high HIV prevalence: Implications for prevention. The Lancet 364(9428): 4-6. doi:10.1016/S0140-6736(04)16606-3.

Heckathorn, D.D., Broadhead, R.S., Anthony, D.L., and Weakliem, D.L. (1999). AIDS and social networks: HIV prevention through network mobilization. Sociological 
Focus 32(2): 159-179. http://www.respondentdrivensampling.org/reports/ sociological_focus.pdf.

Hirsch, J.S., Higgins, J., Bentley, M.E., and Nathanson, C.A. (2002). The social construction of sexuality: Marital infidelity and sexually transmitted disease HIV risk in a Mexican migrant community. American Journal of Public Health 92(8): 1227-1237. doi:10.2105/AJPH.92.8.1227.

Hunter, M. (2005). Cultural politics and masculinities: Multiple-partners in historical perspective in KwaZulu-Natal. Culture, Health \& Sexuality 7(3): 209-223. doi:10.1080/13691050412331293458.

INSR and Macro (2006). Rwanda Demographic and Health Survey 2005. Calverton, Maryland: INSR and ORC Macro.

Isiugo-Abanihe, U.C. (1994). Extramarital relations and perceptions of HIV/AIDS in Nigeria. Health Transition Review 4(2): 111-125. http://htc.anu.edu.au/pdfs/Isiugo1.pdf.

Kaler, A. (2003). "My girlfriends could fill a yanu-yanu bus": Rural Malawian men's claims about their own serostatus. Demographic Research SC1(11): 349-372. doi:10.4054/DemRes.2003.S1.11.

Kaler, A. (2004). AIDS-talk in everyday life: The presence of HIV/AIDS in men's informal conversation in southern Malawi. Social Science \& Medicine 59(2): 285-297. doi:10.1016/j.socscimed.2003.10.023.

Kelly, J.A., Amirkhanian, Y.A., Kabakchieva, E., Vassileva, S., Vassilev, B., McAulifee, T.L., DiFranceisco, W.J., Antonova, R., Petrova, E., Khoursine, R.A., and Dimitrov, B. (2006). Prevention of HIV and sexually transmitted diseases in high risk social networks of young Roma (Gypsy) men in Bulgaria: Randomised controled trial. British Medical Journal 333(7578): 1098-1101. doi:10.1136/bmj.38992.478299.55.

Kimuna, S.R. and Djamba, Y.K. (2005). Wealth and extramarital sex among men in Zambia. International Family Planning Perspectives 31(2): 83-89. doi:10.1363/3108305.

Lagarde, E., Auvert, B., Caraël, M., Laourou, M., Ferry, B., Akam, E., Sukwa, T., Morison, L., Maury, B., Chege, J., N'Doye, I., and Buvé, A. (2001). Concurrent sexual partnerships and HIV prevalence in five urban communities of subSaharan Africa. AIDS 15(7): 877-884. doi:10.1097/00002030-200105040-00008. 
Lurie, M.N., Williams, B.G., Zuma, K., Mkaya-Mwaburi, D., Garnett, G.P., Sweat, M.D., Gittelsohn, J., and Karim, S.S.A. (2003). Who infects whom? HIV-1 concordance and discordance among migrant and non-migrant couples in South Africa. AIDS 17(15): 2245-2252. doi:10.1097/00002030-200310170-00013.

Mitsunago, T.M., Powell, A.M., Heard, N.J., and Larsen, U.M. (2005). Extramarital sex among Nigerian men: Polygyny and other risk factors. JAIDS 39(4): 478-488. http://journals.lww.com/jaids/Fulltext/2005/08010/Extramarital_Sex_Among_Ni gerian_Men_Polygyny_and.18.aspx.

McPherson, M., Smith-Lovin, L., and Cook, J.M. (2001). Birds of a feather: Homophily in social networks. Annual Review of Sociology 27(1): 415-444. doi:10.1146/annurev.soc.27.1.415.

Mishra, V., Bignami-Van Assche, S., Greener, R., Vaessen, M., Hong, R., Ghys, P.D., Boerma, J.T., Van Assche, A., Khan, S., and Rutstein, S. (2007). HIV infection does not disproportionately affect the poorer in sub-Saharan Africa. AIDS 21: S17-S28. doi:10.1097/01.aids.0000300532.51860.2a.

Morris, M. and Kretzschmar, M. (1997). Concurrent partnership and the spread of HIV. AIDS 11(5): 641-648. doi:10.1097/00002030-199705000-00012.

Morris, M. and Kretzschmar, M. (2000). A microsimulation study of the effect of concurrent partnerships on the spread of HIV in Uganda. Mathematical Population Studies 8(2): 109-133. doi:10.1080/08898480009525478.

National Bureau of Statistics and Macro (2005). Tanzania Demographic and Health Survey 2004-2005. Dar es Salaam, Tanzania: National Bureau of Statistics and ORC Macro.

National Statistical Office and Macro (2001). Malawi Demographic and Health Survey 2000. Zomba, Malawi and Calverton, Maryland, USA: National Statistical Office and ORC Macro.

National Statistical Office and Macro (2005). Malawi Demographic and Health Survey 2004. Calverton, Maryland: National Statistical Office and ORC Macro.

Nnko, S., Boerma, J.T., Urassa, M., Mwaluko, G., and Zaba, B. (2004). Secretive females or swaggering males?: An assessment of the quality of sexual partnership reporting in rural Tanzania. Social Science \& Medicine 59(2): 299-310. doi:10.1016/j.socscimed.2003.10.031. 
O'Connor, M.L. (2001). Men who have many sexual partners before marriage are more likely to engage in extramarital intercourse. International Family Planning Perspectives 27(1): 48-49. doi:10.2307/2673807.

Onah, H.E., Iloabachie, G.C., Obi, S.N., Ezugwu, F.O., and Eze, J.N. (2002). Nigerian male sexual activity during pregnancy. International Journal of Gynecology \& Obstetrics 76(2): 219-223. doi:10.1016/S0020-7292(01)00579-3.

Quinn, T.C., Wawer, M.J., Sewankambo, N., Serwadda, D., Li, C., Wabwire-Mangen, F., Meehan, M.O., Lutalo, T., and Gray R.H. (2000). Viral load and heterosexual transmission of Human Immunodeficiency Virus Type 1. New England Journal of Medicine 342(13): 921-929. doi:10.1056/NEJM200003303421303.

Reniers, G. and Tfaily, R. (2008). Polygyny and HIV in Malawi. Demographic Research 19(53): 1811-1830. doi:10.4054/DemRes.2008.19.53.

Schatz, E. (2005). "Take your mat and go!": Rural Malawian women's strategies in the HIV/AIDS era. Culture, Health \& Sexuality 7(5): 479-492. doi:10.1080/13691050500151255.

Shelton, J.D., Halperin, D.T., Nantulya, V., Potts, M., Gayle, H.D., and Holmes, K.K. (2004). Partner reduction is crucial for balanced "ABC" approach to HIV prevention. British Medical Journal 328(7444): 891-893. doi:10.1136/bmj.328.7444.891.

Stoneburner, R.L. and Low-Beer, D. (2004). Population-level HIV declines and behavioral risk avoidance in Uganda. Science 304(5671): 714-718. doi:10.1126/science.1093166.

Trinitapoli, J. and Regnerus, M.D. (2006). Religion and HIV risk behaviors among married men: Initial results from a study in rural sub-Saharan Africa. Journal for the Scientific Study of Religion 45(4): 505-528. doi:10.1111/j.14685906.2006.00325.x.

UNAIDS (2001). HIV prevention needs and successes: A tale of three countries. Geneva, Switzerland.

USAID (2002). What happened in Uganda: Declining HIV prevalence, behavior, change, and the national response. Washington: USAID.

Valente, T.W. and Fosados, R. (2006). Diffusion of innovations and network segmentation: The part played by people in promoting health. Sexually Transmitted Diseases 33(7): S23-S31. doi:10.1097/01.olq.0000221018. 32533.6d. 
Vanlandingham, M., Knodel, J., Saengtienchai, C., and Pramualratana, A. (1998). In the company of friends: Peer influence on Thai male extramarital sex. Social Science \& Medicine 47(12): 1993-2011. doi:10.1016/S0277-9536(98)00274-3.

Varga, C.A. (1997). Sexual decision-making and negotiation in the midst of AIDS: Youth in KwaZulu-Natal, South Africa. Health Transition Review 7(Suppl 3): 45-67. http://htc.anu.edu.au/pdfs/Varga1.pdf.

Watkins, S.C. (2004). Navigating the AIDS epidemic in rural Malawi. Population and Development Review 30(4): 673-705. doi:10.1111/j.1728-4457.2004.00037.x.

Watkins, S.C., Behrman, J.R., Kohler, H.-P., and Zulu, E.M. (2003). Introduction to "Research on demographic aspects of HIV/AIDS in rural Africa". Demographic Research SC1(1): 1-30. doi:10.4054/DemRes.2003.S1.1.

Wilson, D. and Halperin, D.T. (2008). "Know your epidemic, know your response": A useful approach, if we get it right. The Lancet 372(9637): 423-426. doi:10.1016/S0140-6736(08)60883-1.

Wolffers, I., Fernandez, I.. Verghis, S., and Vink, M. (2002). Sexual behaviour and vulnerability of migrant workers for HIV infection. Culture, Health \& Sexuality 4(4): 459-473. doi:10.1080/13691050110143356.

Zapka, J.G., Stoddard, A.M., and McCusker, J. (1993). Social network, support and influence: Relationship with drug use and protective AIDS behavior. AIDS Education and Prevention 5(4): 352-366. 
Clark: Extra-marital sexual partnerships and male friendships in rural Malawi 